\title{
Perpendicular Actuation with Individually Controlled Polymer Microactuators
}

Edwin J ager, Olle Inganäs and Ingemar Lundström

The self-archived postprint version of this journal article is available at Linköping University Institutional Repository (DiVA):

http:/ / urn.kb.se/ resolve?urn=urn:nbn:se:liu:diva-60386

N.B.: When citing this work, cite the original publication.

J ager, E., Inganäs, O., Lundström, I., (2001), Perpendicular Actuation with Individually Controlled Polymer Microactuators, Advanced Materials, 13(1), 76-79. https:// doi.org/ 10.1002/ 1521-

4095(200101)13:1\&1t; 76::AID-ADMA76\&gt;3.0.CO;2-I

Original publication available at:

The published DOI does not work

Link to the journal:

http:// onlinelibrary.wiley.com/journal/ 10.1002/ (ISSN) 1521-4095

Copyright: Wiley

http:/ / eu.wiley.com/WileyCDA/ 


\section{Perpendicular actuation with individually controlled}

\section{polymer microactuators}

By Edwin W. H. Jager, Olle Inganäs, and Ingemar Lundström

Division of Applied Physics,

Department of Physics and Measurement Technology (IFM)

Linköpings universitet

S-581 83, Linköping

Sweden

\section{Abstract}

We are using microactuators based on a conducting polymer, polypyrrole, and demonstrate here a scheme to make true three-dimensional movements. We present a complementary microfabrication method, which was developed in order to create individually addressable and controllable PPy/Au actuators. Using these individually controlled microactuators we are able to obtain movements both out of and in the plane of the substrate surface.

Keywords: electrochemistry, polypyrrole, actuator, bilayer, bimorph, micromachining, micromanipulation, artificial muscle 
A serious drawback of surface micromachining is the fact that structures are limited to a 2D surface. Bulk micromachining is used to create 3D structures but geometries are limited and etching times are long. There are a few ways to overcome this problem. Photopolymerization or photoinduced deposition can be used to build 3D structures [1]. LIGA can be used to fabricate metallic 3D microstructures, which can be used as a mould for casting, hot embossing, or injection moulding. Recently new materials have made it possible to make high aspect ratio structures in thick film photoresist, such as SU-8. These structures can be used as templates for electroplating or polydimethylsiloxane (PDMS) stamps for micro contact printing [2].

Yet another way of building into the vertical dimension is by fabricating free plates using surface micromachining, which are assembled into a 3D system. Pister et al. used hinged polysilicon plates, which are rotated out of plane and assembled into 3D structures [3]. This rotation and assembling is done both by hand and using systems of rods and levers. They have made hollow triangular beams that should become the rigid parts of a robot arm or walking microrobot.[4]. Using similar structures Kiang et al. have fabricated scanning micromirrors that stand perpendicular to the surface [5]. Suzuki et al. made polysilicon plates connected by polyimide hinges. They assembled the plates into cubes and are going to use them as wings for artificial flying insects [6]. Ebefors et al. have demonstrated a 3D anemometer based on an out of plane rotation of the third sensor. Their assembly is based on the thermal expansion of polyimide, deposited in etched $\mathrm{V}$-grooves. When heating the polyimide, the material expands and the silicon plate with the sensor rotates out of plane [7]. The surface tension of molten solder has been used by Green et al. to achieve out of plane rotation of both Ni-plated and single crystal Si plates [8]. They have extended this method by using more CMOS process compatible photoresist as the melting 
material [9]. Smela et al. have used polypyrrole/gold actuators as active hinges to rotate silicon plates out of the surface [10] and on these plates she even made moving "pixels" that can be separately addressed [11].

Microactuators can often move in one plane only. In plane actuation can be found in for instance electrostatically driven comb-drive actuators [12]. Microactuators based on the deflection of a magnetic element on springs in an external magnetic field have been made for both in plane [13] and out of plane [14] actuation depending on the design. Microactuators based on physical phenomena in layered thin films, like electrostatic bending beams [15], thermal expansion beams [16] or redox reaction in polymers [17] only bend out of plane, due to their geometrical construction. For our microactuators we have developed a new fabrication scheme that allows us to make in plane actuators, or even complex 3D motion.

Our microactuators are based on a reversible change of volume due to an oxidation-reduction reaction of conjugated polymers, like polypyrrole and polyaniline. These materials have been used to make both macro- [18-22] and microactuators [23-25]. For the microactuators we normally use polypyrrole doped with dodecyl benzene sulfonate ions (PPy(DBS)). Applying a negative potential (-1 $\mathrm{V}$ vs. $\mathrm{Ag} / \mathrm{AgCl})$, we reduce the PPy to its neutral state $\left(\mathrm{PPy}^{0}\left(\mathrm{M}^{+} \mathrm{DBS}-\right)\right)$. To maintain charge neutrality in the PPy, cations $\left(\mathrm{M}^{+}\right)$migrate into the PPy from an ion source/sink, in our case a NaDBS aqueous electrolyte solution and the material swells. When applying a positive potential ( $\sim \mathrm{V})$, we oxidise the PPy $\left(\mathrm{PPy}^{+}\left(\mathrm{DBS}^{-}\right)\right)$. The cations now move out of the PPy back into the electrolyte and the material shrinks. The electrochemical process can be written as

$$
\mathrm{PPy}^{+}\left(\mathrm{DBS}^{-}\right)+\mathrm{M}^{+}(\mathrm{aq})+\mathrm{e}^{-} \leftrightarrow \mathrm{PPy}^{0}(\mathrm{MDBS})
$$


The swelling and shrinking of the polymer can be used to make actuators by combining a layer of the electro-active PPy with a passive Au layer in a bilayer configuration. The Au layer acts both as a structural layer and an electrode. Now the swelling/shrinking is transformed into a bending motion.

In our laboratory we have developed microactuators, also called micromuscles, based on the PPy(DBS)/Au bilayer [26]. The microactuators were used to lift plates, to open and close boxes [23], to grab microscale objects, and close microvials [25], to lift silicon plates [10], and as an active element in moving "pixels" [11]. We have demonstrated full control of the movement of a microrobotic arm [27]. With this arm we have lifted and moved micrometer-sized objects over a distance of $270 \mu \mathrm{m}$. The controlled movement of the robot arm is due to individually controlled microactuators. The arm is however not capable of extensive movement in the plane parallel to the substrate surface. The same principles for fabrication of the microrobot can however be used to make more complex actuator structures. Here, we demonstrate a scheme for true three-dimensional movements, where a sequence of individual actuators is used in a cascading manner, so that the movement of the first actuator moves the base of the second actuator. This creates considerable degrees of freedom of movement, but we limit ourselves to the first generation of these structures, where perpendicular actuation is realised with surface micromachining.

In order to make perpendicular actuators we set two actuators at right angles. A rigid plate mechanically connected the actuators to each other. In our case we used a photopatternable resin called benzocyclobutene (BCB). We used the first actuator to rotate the device off the substrate and set it perpendicular to the surface. Then, we activated the second actuator, which now moved in plane. Fig. 1 shows this schematically. We have also made a third actuator that should move a plate with a slit so that they would lock the device in this perpendicular position to give it more 
mechanical strength. However, we have not yet succeeded in this. A picture of this third actuator with plate can be seen in Fig. 3, but is omitted from Fig. 1 for clarity.

To make the perpendicular actuators, we need individually addressable hinges. This required some modifications of our previous designs. First, we needed an insulating substrate. We chose to use a thermally oxidised Si wafer. The individual controllability also required separate gold electrodes for each hinge. As the electrodes or hinges were mechanically connected in the rigid parts made of $B C B$, this led to $B C B$ in contact with the substrate. Therefore we could not use the differential adhesion method [28]. This method is based on the poor adhesion of $\mathrm{Au}$ on $\mathrm{Si}$, but as also $\mathrm{BCB}$, which adheres well on $\mathrm{Si}$, would come into contact with $\mathrm{Si}$, the structures would stick to the substrate. Release would be impossible. Therefore we used a sacrificial layer. In the first micromuscles we had used photoresist as a sacrificial layer [26], but the differential adhesion method gave better results. We have also made microactuators with a PECVD $\mathrm{SiO}_{x}$ as a sacrificial layer on a $\mathrm{Si}$ substrate, but on a thermally oxidised Si substrate we could not use this. Therefore we used $\mathrm{Ti}$ in the present layout as the sacrificial layer.

A 4" Si-wafer was thermally oxidized leading to a $1 \mu \mathrm{m}$ thick $\mathrm{SiO}_{2}$ layer. On that layer we thermally evaporated $700 \AA \mathrm{Ti}$ as a sacrificial layer. Using standard photolithographic techniques we patterned this layer (Fig. 2 A). On this a structural Au layer, $2000 \AA$ thick (with a $30 \AA \mathrm{Cr}$ adhesion layer) was thermally evaporated. Next, slits were wet chemically etched in the Cr/Au (Fig. 2 B). These slits separated the electrodes/actuators. We only etched the slits and not the complete electrode/actuator layout because we wanted to keep the Au layer intact for as long as possible. If we kept the Au layer intact until the PPy electropolymerisation step, we could grow PPy on all the actuators simultaneously. Hereafter, we deposited the BCB (benzocyclobutene Cyclotene 4042-40, Dow Chemical) layer by photopolymerisation. The $\mathrm{BCB}$ layer was $2.2 \mu \mathrm{m}$ thick. The $\mathrm{BCB}$ formed the rigid 
parts and connected the individual actuators (Fig. 2 C). A $950 \mathrm{~nm}$ layer of PPy was electropolymerised from a $0.1 \mathrm{M} \mathrm{NaDBS}$ and $0.1 \mathrm{M}$ pyrrole monomer solution at a voltage of $0.55 \mathrm{~V}$ vs. $\mathrm{Ag} / \mathrm{AgCl}$. To pattern the PPy, we masked the Au coated wafer with a patterned photoresist layer. The PPy polymerised on the parts of the Au that were not covered with photoresist. Fig. $2 \mathrm{D}$ shows the result after the photoresist had been removed.

A photoresist pattern of the complete device including wires and contact pads was deposited. We gave the resist a hard bake of 20 minutes at $110^{\circ} \mathrm{C}$. The resist pattern overlapped the PPy structures by $5 \mu \mathrm{m}$ to protect the PPy from the $\mathrm{Au}, \mathrm{Cr}$ and $\mathrm{Ti}$ etchants. We etched the $\mathrm{Au}$ and $\mathrm{Cr}$ and under etched the sacrificial Ti layer. Then we diced the wafer. Finally, we removed the photoresist using ethanol and the actuators were free, ready to be activated. In this device the actuators for in plane movement were connected to the substrate by another microactuator (that should rotate them out of the substrate plane) and a contact wire (shown in grey in the right hand side of Fig. 2 E).

We mounted a dice in an electrochemical cell filled with a 0.1M NaDBS electrolyte. As a counter electrode (CE) we used an $\mathrm{Au}$ wire and an $\mathrm{Ag} / \mathrm{AgCl}$ electrode (BioAnalytical Systems) as a reference (RE). All potentials measured were versus $\mathrm{Ag} / \mathrm{AgCl}$. We contacted the actuators using Au coated probe tips (Karl Suss). To electrochemically control the microactuators we used a custom-modified potentiostat, AutoLab PGSTAT10 (EcoChemie), with 6 individually controlled working electrodes (WE) vs. one CE and one RE. The movement was recorded using a long working distance microscope and CCD-camera connected to a VCR. The still pictures were taken using a frame grabber.

To initiated the activation, we ran 5-10 cyclic voltammetry (a triangular wave potential) sweeps of $0 \mathrm{~V}$ to $-1.0 \mathrm{~V}$ at $100 \mathrm{mV} / \mathrm{son}$ all hinges simultaneously. These initial sweeps are used to activate the PPy/Au bilayers to their maximum range. 
Hereafter, we individually controlled the actuators. We controlled the degree of bending by varying the applied voltage (using the amount of consumed charge is another option to control the movement). By applying a voltage between $0.2 \mathrm{~V}$ and $1.0 \mathrm{~V}$ we could bend each hinge at any intended angle.

Fig. 3 shows a picture of the movement of the in plane actuator. For clarity the device is only tilted a few degrees. For a full motion sequence of the truly perpendicular actuation we refer to our homepage ${ }^{1}$. We used one actuator (actuator 2 in Fig. 3) as an active hinge to rotate the device perpendicular to the surface. Then the other actuator (actuator 1 in Fig. 3) could move in plane. We also made a third actuator (actuator 3 in Fig. 3), which should lock the device in its perpendicular position, similar to the locking of Si plates [3]. However, this seemed more difficult to accomplish, due to, amongst other, process variation, which made this third actuator bend with a torsion. Although we could not lock the device, our new design clearly shows that it is possible to obtain complex three-dimensional motion by sequentially activating the active hinges and locking mechanisms. Further, it showed that using the right design, layout and activation order, it is possible to automatically build complicated 3D structures.

We have used the perpendicular actuator as a manipulator. In front of the tip we placed a $100 \mu \mathrm{m}$ glass bead (Aldrich). We cycled the potential once to stretch and flex the tip and shot the glass bead over a distance of $\sim 80 \mu \mathrm{m}$. Fig. 4 shows the pictures with the position of the glass bead before and after the potential cycle.

We have used our latest processing method to create individually controlled micromuscles [27] to fabricate microactuators that move in plane instead of out of plane. This was done by first rotating the actuator perpendicular to the surface by another actuator. Using this method, complex 3D structures could be built. While we here limit the number of cascading actuators to 2 , extending the number of hinges 
and controlling the size and shape of each plate carrying the hinge, could lead to much more complex structures

An advantage of our "active hinges" is that we can eliminate the amount of dead area on the chip. Other methods to assemble 3D microstructures made in poly silicon require ingenious but complex systems using comb drive actuators and push or pull rods to rotate the plate out of the surface plane. Also, most other actuators cannot be operated in a liquid environment. Our PPy/Au microactuators have been shown to work not only in salt solutions but also in blood plasma, urine, and cell culture medium. Therefore we believe that they are well suited for biological applications, like mechanical stimulation of cells. Putting two of these actuators besides each other would create a pair of tweezers for instance for the manipulation of biological entities like single cells, bacteria, and multi-cellular organisms. Microsquid structures used for arresting and positioning cells could be a suitable target; fishing nets may have similarities to these. The microactuators can easily be reduced in lateral size by one order of magnitude.

As mentioned before, we used large CE and RE to activate the perpendicular actuators. We have previously demonstrated on-chip microCE and RE for the PPy/Au microactuators [29]. Using the on-chip electrodes would further miniaturise the system.

${ }^{1}$ A film showing the full movement of this sequence and other microactuator devices can be found at our homepage: http://www.ifm.liu.se/Applphys/ConjPolym/XX.html 


\section{References}

[1] H. Westberg, M. Boman, S. Johansson, J. A. Schweitz, Journal of Applied Physics 73 (1993) 7864.

[2] Y. Xia, G. M. Whitesides, Angewandte Chemie Int. Ed. 37 (1998) 550.

[3] K. S. J. Pister, M. W. Judy, S. R. Burgett, R. S. Fearing, Sensors and actuators A 33 (1992) 249.

[4] R. Yeh, E. J. J. Kruglick, K. S. J. Pister, Journal of Microelectromechanical Systems 5 (1996) 10.

[5] M.-H. Kiang, O. Solgaard, K. Y. Lau, Richard S. Muller, Journal of Microelectromechanical Systems 7 (1998) 27.

[6] K. Suzuki, I. Shimoyama, H. Miura, Journal of Microelectromechanical Systems 3 (1994) 4.

[7] T. Ebefors, E. Kälvesten, G. Stemme, IEEE Int. Workshop on MicroElectroMechanical Sytems (MEMS'98) (Heidelberg, Germany), Three Dimensional Silicon Triple-hot-wire Anemometer based on Polyimide, pp. 93 (1998).

[8] P. W. Green, R. R. A. Syms, E. M. Yeatman, Journal of Microelectromechanical Systems 4 (1995) 170.

[9] R. R. A. Syms, Journal of Microelectromechanical Systems 6 (1999) 448.

[10] E. Smela, M. Kallenbach, J. Holdenried, Journal of Microelectromechanical Systems 8 (1999) 373.

[11] E. Smela, Advanced Materials 11 (1999) 1343.

[12] C.-J. Kim, A. P. Pisano, R. S. Muller, Journal of Microelectromechanical Systems 1 (1992) 31. 
[13] J. W. Judy, R. S. Muller, H. H. Zappe, Solid-State Sensor and Actuator Workshop (Hilton Head `94) (Hilton Head Island, Sc), Magnetic microactuation of polysiliconflexure structures, pp. 43 (1994).

[14] C. Liu, T. Tsao, Y.-C. Tai, T.-S. Leu, C.-M. Ho, W.-L. Tang, D. Miu, Proceedings IEEE Micro Electro Mechanical Systems 1995 (Cat. No.95CH35754) (Amsterdam, Netherlands), Out-of-plane permalloy magnetic actuators for delta-wing control, pp. 7 (1995).

[15] M. Elwenspoek, L. Smith, B. Hök, J. Micromech. Microeng. 2 (1992) 221.

[16] G. Lin, C.-J. Kim, S. Konishi, H. Fujita, Transducers '95 (Stockholm, Sweden), Design, fabrication, and testing of a C-shaped Actuator, pp. 416 (1995).

[17] E. Smela, O. Inganäs, I. Lundström, Transducers '95 (Stockholm, Sweden), Self-opening and closing boxes and other micromachined folding structures, pp. 350 (1995).

[18] R. H. Baughman, L. W. Shacklette, R. L. Elsenbaumer, E. J. Plichta, C. Becht, in P. I. Lazarev (Ed.): Molecular Electronics, Kluwer Academic Publishers, Dordrecht 1991, p. 267.

[19] Q. Pei, O. Inganäs, I. Lundström, Smart mater. Struct. 2 (1993) 1.

[20] T. F. Otero, J. M. Sansinena, Proceedings of the SPIE --The International Society for Optical Engineering. 2779 (1996) 365.

[21] A. Della Santa, D. De Rossi, A. Mazzoldi, Smart Mater. Struct. 6 (1997) 23.

[22] M. R. Gandhi, P. Murray, G. M. Spinks, G. G. Wallace, Synth. Met. 73 (1995) 247.

[23] E. Smela, O. Inganäs, I. Lundström, Science 268 (1995) 1735.

[24] A. P. Lee, K. C. Hong, J. Trevino, M. A. Northrop, Dynamic and Systems and Control Session, International Mechanical Engineering Congress (Chicago, 
USA), Thin film conductive polymer for microactuator and micromuscle applications, pp. 725 (1994).

[25] E. W. H. Jager, E. Smela, O. Inganäs, I. Lundström, Smart Structures and Materials, EAPAD'99 (Newport Beach, CA, USA), Applications of polypyrrole microactuators, pp. 377 (1999).

[26] E. Smela, O. Inganäs, Q. Pei, I. Lundström, Advanced Materials 5 (1993) 630.

[27] E. W. H. Jager, O. Inganäs, I. Lundström, Science 288 (2000) 2335.

[28] E. Smela, O. Inganäs, I. Lundström, Transducers '95 (Stockholm, Sweden), Differential adhesion method for microstructure release: an alternative to the sacrificial layer, pp. 218 (1995).

[29] E. W. H. Jager, E. Smela, O. Inganäs, Sensors \& Actuators B: Chemical 56 (1999) 73. 
Fig. 1 A sketch of the movement. (1.) After the fabrication the device is laying on the surface. (2.) By activating the first microactuator, the device rotates from the surface in a perpendicular state. (3.) By activating the second actuator the tip bends up to $180^{\circ}$. By cycling the voltage on the second actuator, the tip bends and straightens. Not shown is the third actuator that should lock the whole device. 
Fig.1
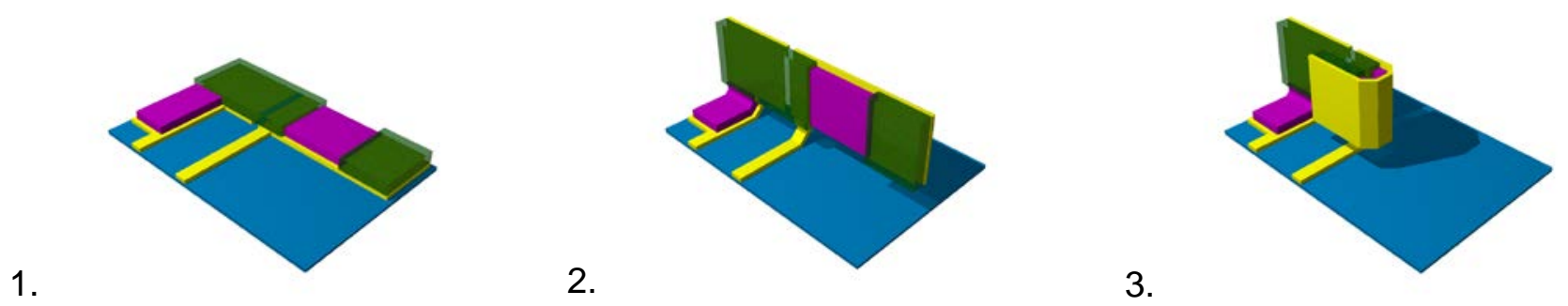

3. 
Fig. 2 A schematic drawing of the process steps for fabricating perpendicular microactuators. (A) Deposit and pattern the sacrificial Ti layer. (B) Evaporate $\mathrm{Cr}$ and $\mathrm{Au}$, etch insulating strips. (C) Photopolymerise BCB rigid elements. (D) Electropolymerise PPy in patterned photoresist windows. (E) Etch the final device shape, including wires and contact pads. Remove the sacrificial layer to achieve a free standing structure. The free hanging, perpendicular microactuator is connected to the substrate by a microactuator and a contact wire (shown in grey in the right hand side). 
Fig. 2

Top view

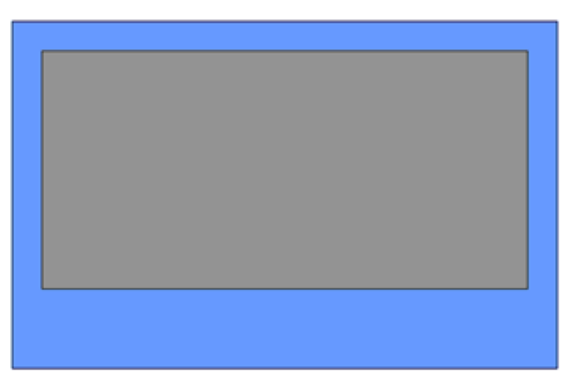

A.

B.

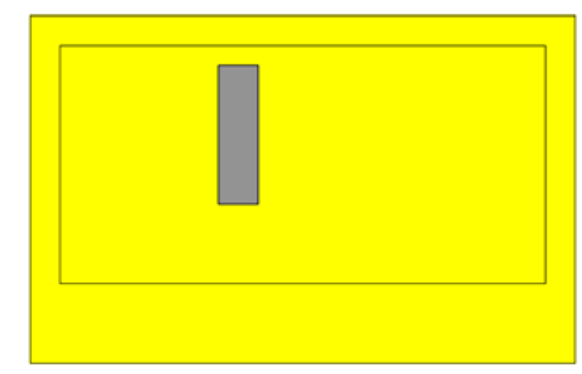

C.

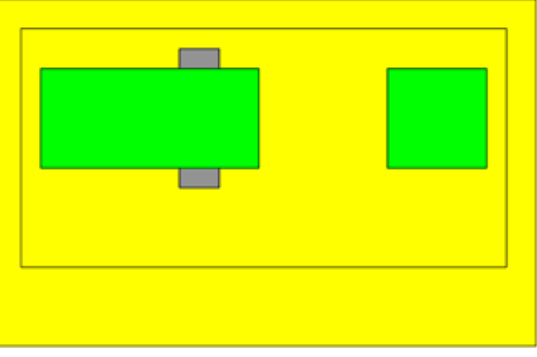

D.

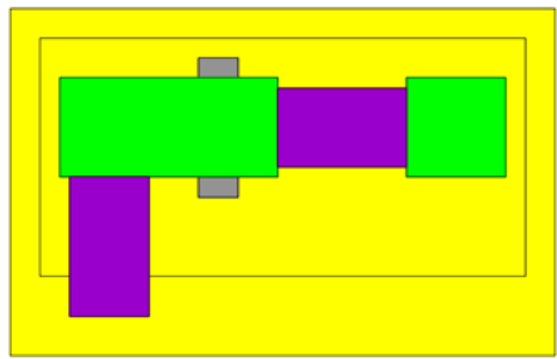

Cross section A-A
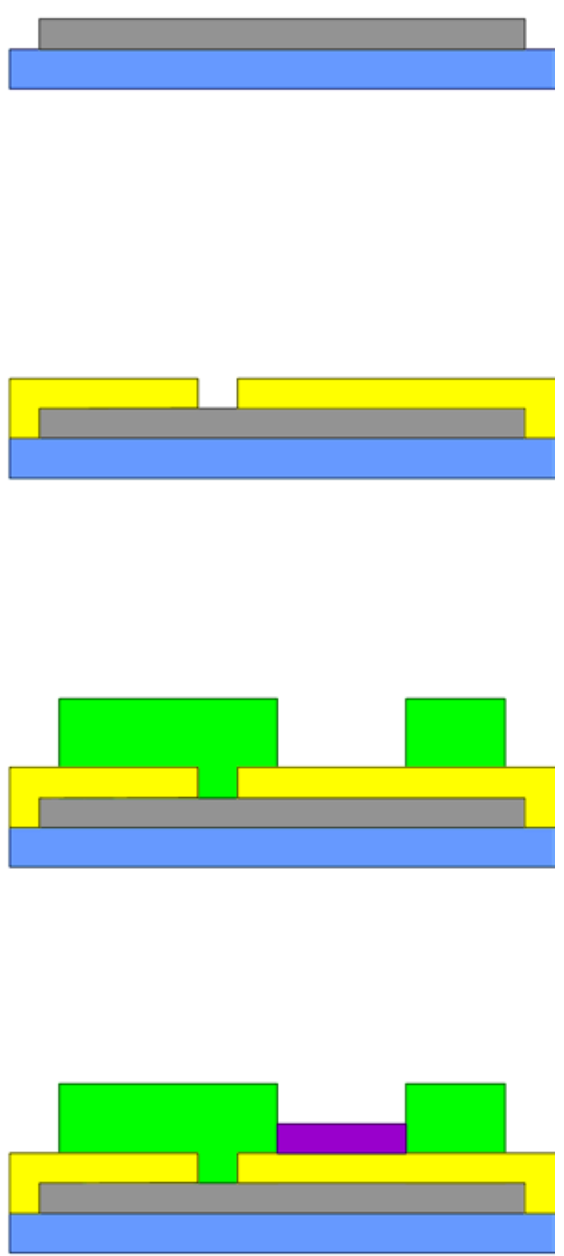
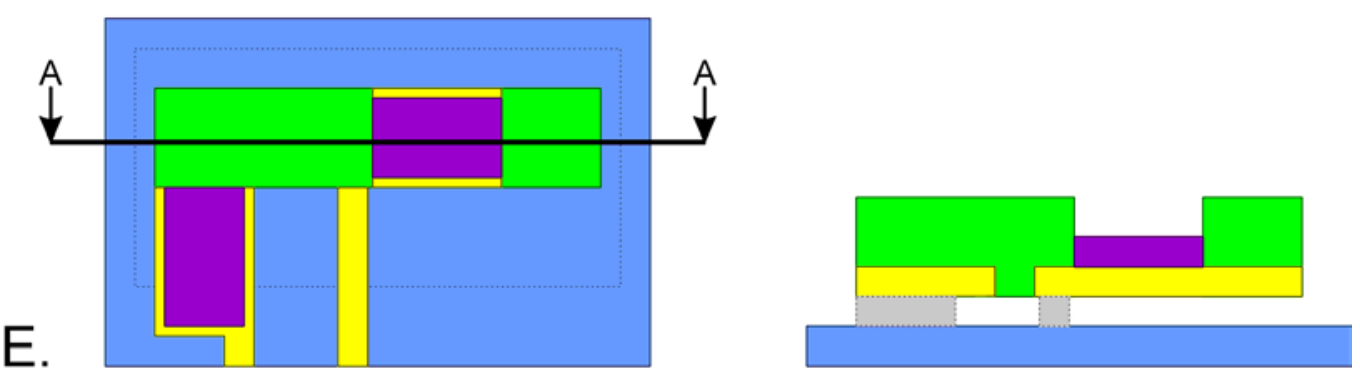

$\square \mathrm{SiO} \square \mathrm{Ti} \square \mathrm{Au} \square$ BCB $\square$ PPy 
Fig. 3 Two pictures of the movement of the tip. To be able to see better, we have bent the whole device at a small angle instead of setting it perpendicular to the surface. Actuator 1 bent the tip. Actuator 2 controlled the angle with respect to the surface of the device. Actuator 3 should move a plate with a slit over the device in other to keep it locked in the perpendicular state and thus supply some strength to the device. Here actuator 3 is bent almost flat $\left(\mathrm{V}_{\text {applied }}=-0.7 \mathrm{~V}\right)$. 
Fig. 3
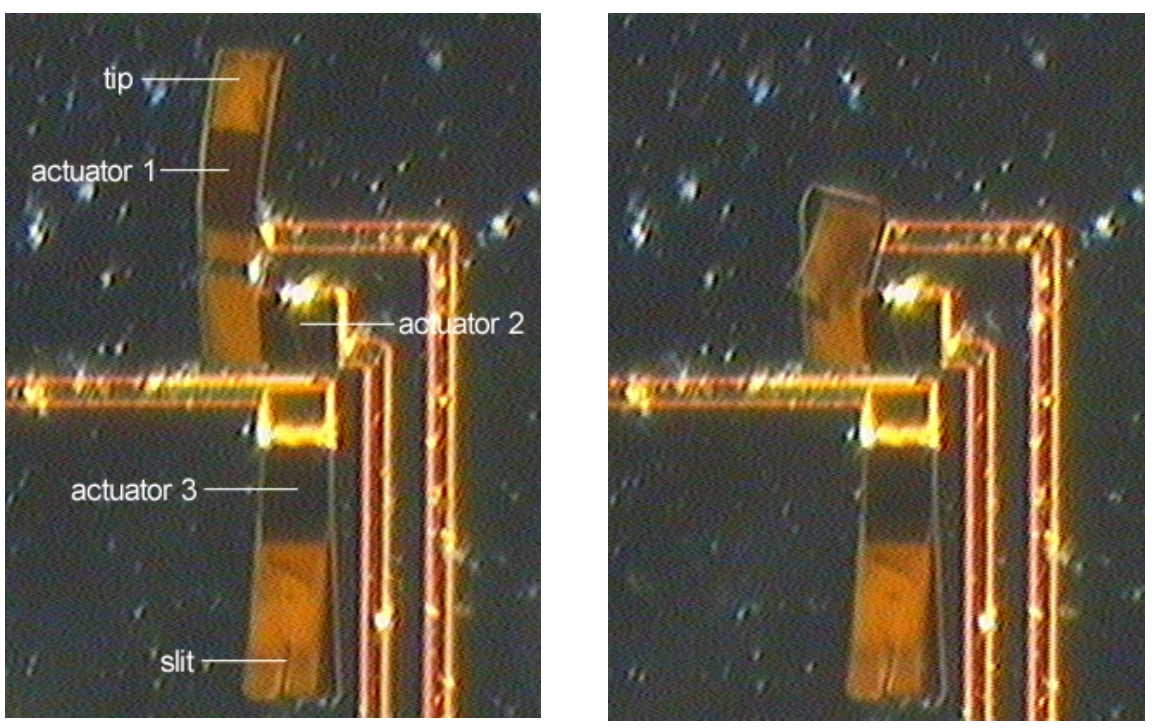
Fig. 4 Pictures of the actuator kicking a glass bead. The device stands perpendicular to the surface. We put a glass bead $(-100 \mu \mathrm{m}$ in diameter) in front of the bent tip (1.). We cycled the tip once and shot away the glass bead over a distance of $\sim 80 \mu \mathrm{m}$ (2). 
Fig. 4

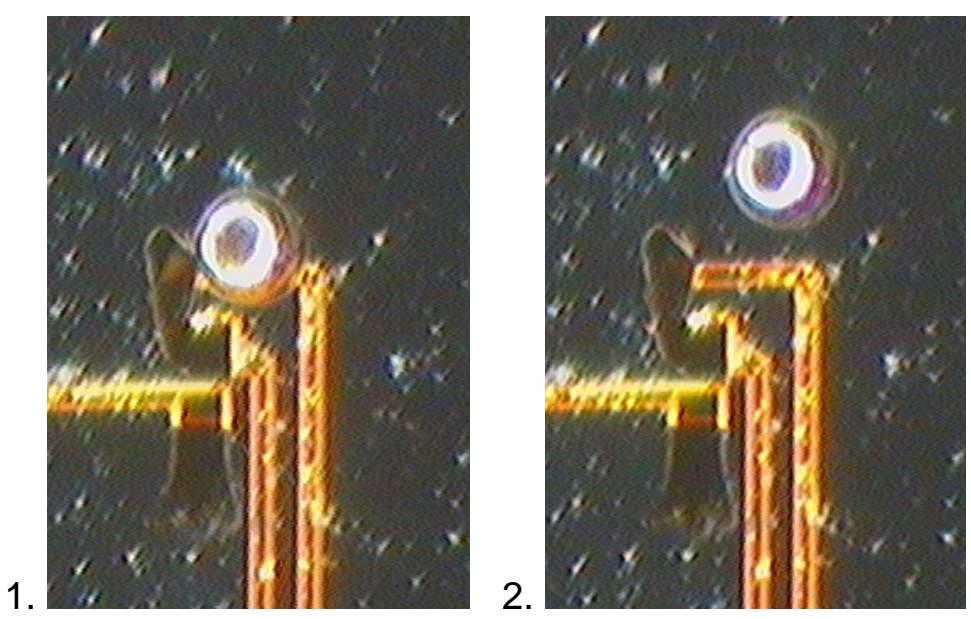

